\title{
PENGARUH KEPEMIMPINAN, KOMUNIKASI, DAN KOMPENSASI TERHADAP MOTIVASI KERJA PEGAWAI PADA DINAS PENDAPATAN, PENGELOLAAN KEUANGAN DAN ASET DAERAH KABUPATEN SOPPENG
}

\author{
The Effect of Leadership, Communication, and Compensation to Work Motivation of Employee at the \\ Department of Revenue, Financial and Regional Asset Management Regency of Soppeng
}

\author{
Hasmin $^{1}$ Gunawan $^{2}$ Andi Asriani ${ }^{3}$ \\ ${ }^{I}$ Manajemen, PPs STIE Nobel Indonesia \\ E-mail: hasmintamsah@gmail.com \\ ${ }^{2}$ Manajemen, PPs STIE Amkop Makassar \\ E-mail:fadhelgun@yahoo.co.id \\ ${ }^{3}$ Manajemen, PPs STIE Amkop Makassar \\ E-mail: asrianidppkad@gmail.com
}

\begin{abstract}
ABSTRAK
Faktor komunikasi merupakan salah satu faktor yang memberikan pengaruh terhadap motivasi pegawai. Penelitian ini bertujuan untuk 1) Mengetahui pengaruh kepemimpinan terhadap motivasi kerja pegawai Dinas Pendapatan, Pengelolaan Keuangan dan Aset Daerah Kabupaten Soppeng. 2) Mengetahui pengaruh komunikasi terhadap motivasi kerja pegawai Dinas Pendapatan, Pengelolaan Keuangan dan Aset Daerah Kabupaten Soppeng. 3) Mengetahui pengaruh kompensasi terhadap motivasi kerja pegawai Dinas Pendapatan, Pengelolaan Keuangan dan Aset Daerah Kabupaten Soppeng. 4) Mengetahui pengaruh kepemimpinan, komunikasi dan kompensasi terhadap motivasi kerja pegawai Dinas Pendapatan, Pengelolaan Keuangan dan Aset Daerah Kabupaten Soppeng. Penelitian ini dilaksanakan pada Dinas Pendapatan, Pengelolaan Keuangan dan Aset Daerah Kabupaten Soppeng dengan jumlah populasi sebanyak 134 orang pegawai. Sampel penelitian ini ditentukan dengan menggunakan teknik pengambilan sampel acak sederhana dengan jumlah sampel sebanyak 58 orang pegawai. Analisis data dalam penelitian ini menggunakan, uji validitas dan reliabilitas, asumsi klasik, dan analisis regresi linier berganda. Hasil penelitian menunjukkan bahwa 1) Kepemimpinan berpengaruh positif dan signifikan terhadap motivasi kerja pegawai Dinas Pendapatan, Pengelolaan Keuangan dan Aset Daerah Kabupaten Soppeng, 2) Komunikasi berpengaruh positif dan signifikan terhadap motivasi kerja pegawai Dinas Pendapatan, Pengelolaan Keuangan dan Aset Daerah Kabupaten Soppeng, 3) Kompensasi berpengaruh positif dan signifikan terhadap motivasi kerja pegawai Dinas Pendapatan, Pengelolaan Keuangan dan Aset Daerah Kabupaten Soppeng. 4) Kepemimpinan, komunikasi dan kompensasi secara simultan berpengaruh positif dan signifikan terhadap motivasi kerja pegawai Dinas Pendapatan, Pengelolaan Keuangan dan Aset Daerah Kabupaten Soppeng.
\end{abstract}

Kata Kunci: Kepemimpinan, Komunikasi, Kompensasi, Motivasi Kerja

\begin{abstract}
Communication factor is one of the factors that influence on employee motivation. The aim of the study was to: 1) Know the effect of Leadership to Work Motivation of Employee at the Department of Revenue, Financial and Regional Asset Management Regency of Soppeng. 2) Know the effect of Communication to Work Motivation of Employee at the Department of Revenue, Financial and Regional Asset Management Regency of Soppeng. 3) Know the effect of Compensation to Work Motivation of Employee at the Department of Revenue, Financial and Regional Asset Management Regency of Soppeng. 4) Know the effect of Leadership, Communication, and Compensation to Work Motivation of Employee at the Department of Revenue, Financial and Regional Asset Management Regency of Soppeng. The study was condute at the Department of Revenue, Financial and Regional Asset Management Regency of Soppeng, with population of 134 employees. Sample was the random sampling with 58 employees as samples. Analysis of the data in this study using validity and reliability test, classical assumption test, and multiple linear regression analysis. The result of study indicates that 1) Leadership has positive and significant influence to Work Motivation of Employee at the Department of Revenue, Financial and Regional Asset Management Regency of Soppeng, 2) Communication has positive and significant influence to Work Motivation of Employee at the Department of Revenue,
\end{abstract}


Financial and Regional Asset Management Regency of Soppeng, 3) Compensation has positive and significant influence to Work Motivation of Employee at the Department of Revenue, Financial and Regional Asset Management Regency of Soppeng, 4) Leadership, Communication, and Compensation simultaneously have significant influence to Work Motivation of Employee at the Department of Revenue, Financial and Regional Asset Management Regency of Soppeng.

Keywords: Leadership, Communication, Compensation, Work Motivation

\section{PENDAHULUAN}

Pegawai merupakan ujung tombak dalam upaya peningkatan kinerja organisasi sehingga tujuan organisasi dapat tercapai. Dalam hal ini, pegawai dalam melaksanakan tugas dan tanggung jawab yang diamanahkan, ada faktor kebutuhan yang mendasar sehingga akan memacu seorang pegawai menunjukkan kemampuan kerja yang lebih baik. Artinya, para pegawai bekerja dengan tujuan untuk memenuhi kebutuhan dan keinginan pegawai sehingga dapat menumbuhkan motivasi yang lebih baik. Salah satu indikator yang dapat dinilai bahwa pegawai bekerja dengan harapan dapat memperoleh gaji/upah untuk memenuhi kebutuhannya.

Saat ini, kebutuhan yang sangat kompleks terutama dalam hal masalah kebutuhan sandang, pangan, perumahan, pendidikan, serta istirahat kerja yang cukup, yang perlu mendapatkan skala prioritas utama dalam hal pemenuhannya. Disamping itu, pemenuhan kebutuhan dari para pegawai terhadap pelayanan maupun penghargaan dari atasan terhadap prestasi kerja yang dihasilkan pegawai yang sesuai dengan prinsip keadilan, sehingga berdampak kepada motivasi kerja pegawai.

Menurut Uno (2012), bahwasanya motivasi merupakan salah satu faktor yang turut menentukan kinerja seseorang. Dalam artian, besar kecilnya pengaruh motivasi pada kinerja seseorang akan tergantung kepada berapa banyak intensitas motivasi yang diberikan kepadanya. Dengan demikian, motivasi yang tinggi tersebut akan mampu mendorong seseorang untuk bertindak atau berbuat sesuai dengan yang diharapkan.

Motivasi kerja pegawai pada Dinas Pendapatan, Pengelolaan Keuangan dan Aset Daerah (DPKAD) Kabupaten Soppeng perlu untuk dikaji lebih lanjut, dikarenakan berdasarkan pengamatan peneliti bahwa motivasi pegawai pada DPKAD cenderung rendah. Salah satu fenomena yang terlihat yaitu terkait dengan jam masuk kantor, dimana hampir sebagian besar pegawai datang terlambat dengan berbagai alasan meskipun ada sebagian kecil pegawai yang justru tepat waktu bahkan datang lebih awal. Disisi lain, adanya anggapan sebagian pegawai bahwa mereka digaji tanpa melihat seberapa besar bobot kerjanya, artinya melaksanakan pekerjaan sebanyak apapun tidak akan mempengaruhi naik turun gaji yang mereka terima. Apabila merujuk pada fenomena yang terjadi yang menunjukkan bahwa adanya kecenderungan motivasi pegawai pada Dinas Pendapatan, Pengelolaan Keuangan dan Aset Daerah (PPKAD) Kabupaten Soppeng masih rendah, sehingga perlunya peningkatan motivasi kerja pegawai yang lebih baik. Ada beberapa faktor yang dapat mempengaruhi motivasi kerja pegawai semakin meningkat yaitu diantaranya kepemimpinan, komunikasi dan kompensasi.

Faktor yang pertama mempengaruhi motivasi kerja pegawai adalah kepemimpinan. Menurut George R. Terry dalam Thoha (2012), menjelaskan kepemimpinan sebagai aktivitas untuk mempengaruhi orang-orang agar diarahkan mencapai tujuan organisasi. Apabila disederhanakan fungsi kepemimpinan adalah memastikan karyawannya mendapatkan segala kebutuhan dalam kegiatan kerja, yang selanjutnya akan melancarkan proses pencapaian tujuan organisasi.

Disamping kepemimpinan, faktor komunikasi juga merupakan salah satu faktor yang memberikan pengaruh terhadap motivasi pegawai. Komunikasi antar pegawai ini perlu dibangun dengan baik sehingga pegawai memiliki motivasi tingggi dalam melaksanakan tugas dan tanggung jawabnya dengan baik. Menurut Effendy dalam Alice (2004), mengatakan bahwa komunikasi pada hakekatnya adalah proses penyampaian pikiran atau perasaan oleh komunikator kepada komunikan. Robbins (2006), mengatakan bahwa salah satu kekuatan yang paling menghambat suksesnya kinerja pegawai adalah kurangnya komunikasi yang efektif. 
Artinya, komunikasi yang efektif akan menjadikan pegawai untuk senantiasa dapat bertahan untuk bekerja di lingkungan dimana para pegawai bekerja.

Faktor berikutnya yang juga dapat mempengaruhi motivasi kerja pegawai yaitu kompensasi pegawai. Berkaitan dengan kompensasi Hasibuan (2006), menyatakan pendapatnya bahwasanya kompensasi adalah semua pendapatan yang berbentuk uang, barang langsung atau tidak langsung yang diterima karyawan sebagai imbalan atas jasa yang diberikan kepada perusahaan. Uang merupakan faktor yang kuat dalam memberikan motivasi kerja pada pegawai. Namun konsistensi dari pendapatan, keamanan serta kekuatan kerja sama pentingnya.

Motivasi kerja pegawai, sebagaimana yang diuraikan sebelumnya menjelaskan bahwa faktor kepemimpinan, komunikasi, dan bahkan kompensasi memegang peranan penting dalam mengubah tingkat motivasi kerja pegawai, di mana apabila kepemimpinan, komunikasi, dan kompensasi berjalan sesuai dengan yang diharapkan oleh pegawai, maka akan memotivasi pegawai agar mampu bekerja lebih baik dan sesuai dengan yang diharapkan oleh Dinas Pendapatan, Pengelolaan Keuangan dan Aset Daerah (DPPKAD) Kabupaten Soppeng.

Berdasarkan pemaparan tersebut di atas, maka penulis dapat tertarik untuk melakukan penelitian yang berjudul "Pengaruh Kepemimpinan, Komunikasi, dan Kompensasi terhadap Motivasi Kerja Pegawai pada Dinas Pendapatan, Pengelolaan Keuangan dan Aset Daerah Kabupaten Soppeng”.

\section{METODE PENELITIAN}

\section{Tempat dan Waktu Penelitian}

Penelitian dilaksanakan di Dinas Pendapatan, Pengelolaan Keuangan dan Aset Daerah Kabupaten Soppeng. Adapun pelaksanaan penelitian akan berlangsung selama 1 (satu) bulan.

\section{Populasi dan Sampel Penelitian}

Adapun populasi dalam penelitian ini adalah seluruh pegawai pada Dinas Pendapatan, Pengelolaan Keuangan dan Aset Daerah Kabupaten Soppeng sebanyak 134 orang pegawai. Sampel penelitian ditentukan dengan menggunakan metode Simple Random Sampling (Pengambilan sampel acak sederhana).

Menurut data yang diperoleh, jumlah populasi yaitu sebanyak 134 orang pegawai, sehingga jumlah sampel dapat ditentukan sebagai berikut:

$$
n=\frac{N}{1+N(e)^{2}}=\frac{134}{1+134(0,1)^{2}}=57,26
$$

\section{Metode Pengumpulan Data}

Metode pengumpulan data dalam penelitian ini adalah, menggunakan kuesioner yaitu dengan mengedarkan daftar pertanyaan kepada responden yang ditunjuk untuk mendapatkan data primer berupa kepemimpinan, komunikasi, kompensasi dan motivasi kerja.

\section{Pengujian Hipotesis}

Pengaruh motivasi kepemimpinan, komunikasi dan kompensasi terhadap motivasi kerja pada Dinas Pendapatan, Pengelolaan Keuangan dan Aset Daerah Kabupaten Soppeng, dianalisis dengan menggunakan analisis regresi linear berganda dengan persamaan (Sugiyono, 2009) sebagai berikut :

$$
\mathbf{Y}=\mathbf{a}+\mathbf{b}_{1} \mathbf{X}_{1}+\mathbf{b}_{2} \mathbf{X}_{2}+\mathbf{b}_{3} X_{3}+e
$$

Dimana :

$\mathrm{Y}=$ Motivasi Kerja

$\mathrm{a}=$ bilangan konstan

$b_{1} \ldots b_{2}=$ koefisien regresi

$\mathrm{X}_{1}=$ Kepemimpinan

$\mathrm{X}_{2}=$ Komunikasi

$\mathrm{X}_{3}=$ Kompensasi

$\mathrm{e}=$ error

\section{HASIL PENELITIAN}

\section{Uji Validitas}

Table 1 menunjukkan dasar pertimbangan yang digunakan untuk uji validitas adalah dengan membandingkan antara nilai $r$ hitung terhadap cut of point yang disyaratakan. Sebagaimana yang dikemukakan oleh Sugiyono (2009) bahwa jika nilai $r \geq 0,30$ atau sig $<0,05$ dinyatakan valid, sebaliknya apabila nilai $r$ $<0,30$ atau sig $\geq 0,05$ dinyatakan invalid (tidak valid). 
Tabel 1. Hasil Uji Validitas Variabel

\begin{tabular}{cccc}
\hline Item Pertanyaan & r hitung & Cut of Point $(0,3)$ & Keterangan \\
\hline X1.1 & 0.718 & 0.30 & Valid \\
X1.2 & 0.734 & 0.30 & Valid \\
X1.3 & 0.617 & 0.30 & Valid \\
X1.4 & 0.834 & 0.30 & Valid \\
X1.5 & 0.729 & 0.30 & Valid \\
X2.1 & 0.812 & 0.30 & Valid \\
X2.2 & 0.604 & 0.30 & Valid \\
X2.3 & 0.724 & 0.30 & Valid \\
X2.4 & 0.814 & 0.30 & Valid \\
X2.5 & 0.674 & 0.30 & Valid \\
X3.1 & 0.806 & 0.30 & Valid \\
X3.2 & 0.678 & 0.30 & Valid \\
X3.3 & 0.823 & 0.30 & Valid \\
X3.4 & 0.897 & 0.30 & Valid \\
Y.1 & 0.675 & 0.30 & Valid \\
Y.2 & 0.687 & 0.30 & Valid \\
Y.3 & 0.584 & 0.30 & Valid \\
Y.4 & 0.611 & 0.30 & Valid \\
Y.5 & $0.7 / 6$ & 0.30 & Valid \\
\hline Sumber: Data Primer diolah, 2016 &
\end{tabular}

\section{Uji Reliabilitas}

Berdasarkan hasil uji reliabilitas yang ditunjukkan pada Tabel 2, bahwa seluruh item pertanyaan pada variabel kepemimpinan, komunikasi, kompensasi, dan motivasi kerja diperoleh nilai cronbach alpha lebih besar dari $0,60(0,779 ; 0,778 ; 0,811$; dan 0.649), sehingga dapat disimpulkan bahwa seluruh item pertanyaan pada penelitian ini telah memenuhi syarat reliabilitas. Atau dengan kata lain, bahwa kuisioner ini reliabel sebagai instrument penelitian.

Tabel 2. Hasil Uji Reliabilitas

\begin{tabular}{cccc}
\hline Variabel & Cronbach Aipha & Cut of Point $(0,6)$ & Keterangan \\
\hline Kepemimpinan (X1) & 0.779 & 0.60 & Realibe. \\
Komunikasi (X2) & 0.778 & 0.60 & Realibel \\
Kompensasi (X3) & 0.811 & 0.60 & Realibel \\
Motivasi Kerja (Y) & 0.649 & 0.60 & Realibel \\
\hline Sumber: Data Primer diolah 20i6 & &
\end{tabular}

\section{Uji Hipotesis}

Tabel 3. Hasil Analisis Regresi Linier Berganda

\begin{tabular}{|c|c|c|c|c|c|c|}
\hline & \multirow[t]{2}{*}{ Model } & \multicolumn{2}{|c|}{$\begin{array}{c}\text { Unstandardized } \\
\text { Coefficients }\end{array}$} & \multirow{2}{*}{$\begin{array}{c}\begin{array}{c}\text { Standardized } \\
\text { Cueflicients }\end{array} \\
\text { Beta } \\
\end{array}$} & \multirow[t]{2}{*}{$\mathrm{t}$} & \multirow[t]{2}{*}{ Sig. } \\
\hline & & B & Std. Error & & & \\
\hline \multirow[t]{4}{*}{1} & (Constant) & 3.882 & 1.820 & & 2.133 & .038 \\
\hline & Kepemimpinan & .394 & .103 & .404 & 3.829 & .000 \\
\hline & Komınikasi & 202. & 093 & 261 & 2.394 & 220 \\
\hline & Kompensasi & .256 & .091 & .288 & 2.819 & .007 \\
\hline
\end{tabular}

a. Dependert Variable: Motivasi

Sumbor: Data Primsr dioiah, 2016

Berdasarkan hasil analisis regresi linier berganda yang terlihat pada Tabel 3, maka dapat dibuat persamaan regresi sebagai berikut:

$\mathrm{Y}=3,882+0,394 \mathrm{X}_{1}+0,222 \mathrm{X}_{2}+0,256 \mathrm{X}_{3}+\mathrm{e}$

Dimana :

$\mathrm{Y}=$ Motivasi Kerja

$\mathrm{X}_{1}=$ Kepemimpinan
$\mathrm{X}_{2}=$ Komunikasi

$\mathrm{X}_{3}=$ Kompensasi

$\mathrm{e}=$ error

Pada variabel kepemimpinan (X1) diperoleh nilai $t_{\text {hitung }}$ sebesar 3,829 dengan signifikansi $t$ sebesar 0.000 . Adapun $t_{\text {tabel }}$ dalam penelitian ini yakni sebesar 2,005 $(\mathrm{df}=\mathrm{n}-\mathrm{k}$, dimana $\mathrm{n}=$ jumlah sampel dan $\mathrm{k}$ adalah jumlah variabel). Dikarenakan $t_{\text {hitung }}$ lebih besar dari $t_{\text {tabel }}(3,829>$ $2,005)$ atau signifikansi $\mathrm{t}$ lebih kecil dari 5\% $(0.000<0.05)$, maka secara parsial kepemimpinan (X1) berpengaruh signifikan terhadap motivasi (Y). Berdasarkan atas nilai koefisien regresi standardize $(0,404)$ bertanda positif, mengindikasikan pengaruhnya positif. Artinya kepemimpinan kepemimpinan berpengaruh positif terhadap motivasi. Dengan demikian, Ho ditolak dan Ha diterima sehingga dapat disimpulkan "Terdapat pengaruh positif dan signifikan antara kepemimpinan terhadap motivasi kerja pegawai".

Pada variabel komunikasi (X2) diperoleh nilai $t_{\text {hitung }}$ sebesar 2,394 dengan signifikansi $t$ sebesar 0.020. Adapun $t_{\text {tabel }}$ dalam penelitian ini yakni sebesar 2,005 $(\mathrm{df}=\mathrm{n}-\mathrm{k}$, dimana $\mathrm{n}=$ jumlah sampel dan $\mathrm{k}$ adalah jumlah variabel). Dikarenakan $\mathrm{t}_{\text {hitung }}$ lebih besar dari $\mathrm{t}_{\text {tabel }}(2,394>$ $2,005)$ atau signifikansi t lebih kecil dari 5\% $(0,020<0,050)$, maka secara parsial komunikasi (X2) berpengaruh signifikan terhadap motivasi (Y). Berdasarkan atas nilai koefisien regresi standardize $(0,261)$ bertanda positif, mengindikasikan pengaruhnya positif. Artinya komunikasi berpengaruh positif terhadap motivasi. Dengan demikian, Ho ditolak dan $\mathrm{Ha}$ diterima sehingga dapat disimpulkan "Terdapat pengaruh positif dan signifikan antara komunikasi terhadap motivasi kerja pegawai".

Pada variabel kompensasi (X3) diperoleh nilai $t_{\text {hitung }}$ sebesar 2,819 dengan signifikansi $t$ sebesar 0.007. Adapun $t_{\text {tabel }}$ dalam penelitian ini yakni sebesar 2,005 $(\mathrm{df}=\mathrm{n}-\mathrm{k}$, dimana $\mathrm{n}=$ jumlah sampel dan $\mathrm{k}$ adalah jumlah variabel). Dikarenakan $t_{\text {hitung }}$ lebih besar dari $t_{\text {tabel }}(2,819>$ $2,005)$ atau signifikansi t lebih kecil dari 5\% $(0.007<0.050)$, maka secara parsial kompensasi (X3) berpengaruh signifikan terhadap motivasi (Y). Berdasarkan atas nilai koefisien regresi standardize $(0,288)$ bertanda positif, mengindikasikan pengaruhnya positif. Artinya kompensasi berpengaruh positif terhadap motivasi. Dengan demikian, Ho ditolak dan Ha 
diterima sehingga dapat disimpulkan "Terdapat pengaruh positif dan signifikan antara kompensasi terhadap motivasi kerja pegawai".

Untuk menentukan variabel bebas yang paling dominan mempengaruhi variabel terikat dapat dilihat dari koefisien regresi terstandarisasi (atau beta). Nilai yang paling tinggi mengindikasikan variabel yang paling dominan. Berdasarkan Tabel 3 dapat disimpulkan bahwa variabel kepemimpinan (X1) adalah variabel yang paling dominan mempengaruhi motivasi (Y), dengan koefisien beta sebesar 0,404, kemudian kompensasi sebesar 0,288, serta yang paling rendah yakni komunikasi sebesar 0,261.

Dari hasil perhitungan pada Tabel 4, didapatkan nilai $F_{\text {hitung }}$ sebesar 34,149 (signifikansi $\mathrm{F}=0.000$ ). adapun nilai $\mathrm{F}_{\text {tabel }}$ dalam penelitian ini yakni sebesar $2,78(\mathrm{df} 1=\mathrm{n}-\mathrm{k}$ dan df2=k-1). Dengan demikian, $F_{\text {hitung }}$ lebih besar dari $\mathrm{F}_{\text {tabel }}(34,149>2,78)$ atau Sig F $<5 \%(0.000$ $<0.050)$. Dengan demikian, dapat disimpulkan bahwa Ho ditolak dan Ha diterima, artinya bahwa secara bersama-sama (simultan) variabel bebas yang terdiri dari kepemimpinan (X1), komunikasi (X2) dan kompensasi (X3) berpengaruh signifikan terhadap variabel terikat yaitu motivasi (Y). Hal ini berarti apabila kepemimpinan, komunikasi dan kompensasi dapat ditingkatkan secara bersamasama maka akan berdampak pada peningkatan motivasi kerja pegawai. Begitupun sebaliknya jika kepemimpinan, komunikasi dan kompensasi menurun secara bersama-sama maka akan mengakibatkan penurunan motivasi kerja pegawai.

Tabel 4. Hasil Uji Hipotesis secara Simultan

\begin{tabular}{|c|c|c|c|c|c|c|}
\hline Sodel & & Sum of Squares & df & Mean Square & $\mathrm{F}$ & Sig. \\
\hline \multirow[t]{3}{*}{1} & Regressicn & 258.920 & 3 & 86.307 & 34.149 & $.000^{t}$ \\
\hline & Resicual & 136.476 & 54 & 2.527 & & \\
\hline & Tctal & 395.397 & 57 & & & \\
\hline \multicolumn{7}{|c|}{ a. Predictcrs: (Constart), Kompensasi, Kepemimpinan, Kommikas. } \\
\hline \multicolumn{7}{|c|}{ b. Deperdent Varible: Mctuasi } \\
\hline
\end{tabular}

\section{PEMBAHASAN}

Berdasarkan hasil analisis, diperoleh $t_{\text {hitung }}$ lebih besar daripada $t_{\text {tabel }}(3,829>2,005)$ atau signifikansi t lebih kecil dari $5 \%(0.000<0.050)$ dan nilai koefisien regresi standardize $(0,404)$ bertanda positif, maka dapat disimpulkan bahwa Terdapat pengaruh positif dan signifikan antara kepemimpinan terhadap motivasi kerja pegawai. Artinya, semakin baik kepemimpinan, maka akan semakin tinggi motivasi kerja pegawai Dinas Pendapatan, Pengelolaan Keuangan dan Aset Daerah Kabupaten Soppeng, sebaliknya semakin tidak baik kepemimpinan, maka akan semakin rendah motivasi kerja pegawai Dinas Pendapatan, Pengelolaan Keuangan dan Aset Daerah Kabupaten Soppeng.

Hasil penelitian ini sejalan dengan penelitian yang dilakukan oleh Wahyuningsih et al (2012), menyimpulkan bahwa kepemimpinan berpengaruh positif dan signifikan terhadap motivasi kerja pegawai. Lebih lanjut Wahyuningsih, et al menjelaskan bahwa semakin meningkatnya kepemimpinan maka motivasi kerja pegawai juga mengalami peningkatan. Kemudian pada penelitian yang dilakukan oleh Mulyadi et al (2013), dalam penelitiannya disimpulkan bahwa terdapat pengaruh positif cukup kuat antara peran kepemimpinan dengan motivasi kerja pegawai.

Berdasarkan hasil analisis, diperoleh $t_{\text {hitung }}$ lebih besar daripada $t_{\text {tabel }}(2,394>2,005)$ atau signifikansi t lebih kecil dari $5 \%(0.020<0.050)$ dan nilai koefisien regresi standardize $(0,261)$ bertanda positif, maka dapat disimpulkan bahwa Terdapat pengaruh positif dan signifikan antara komunikasi terhadap motivasi kerja pegawai. Artinya, semakin baik komunikasi, maka akan semakin tinggi motivasi kerja pegawai Dinas Pendapatan, Pengelolaan Keuangan dan Aset Daerah Kabupaten Soppeng. sebaliknya, semakin tidak baik komunikasi, maka akan semakin rendah motivasi kerja pegawai Dinas Pendapatan, Pengelolaan Keuangan dan Aset Daerah Kabupaten Soppeng.

Hasil penelitian ini sejalan dengan penelitian yang dilakukan oleh Hidayah \& Pribadi (2011), bahwa komunikasi memberikan pengaruh positif dan signifikan terhadap motivasi kerja, di mana dalam penelitian ini motivasi kerja pegawai sangat dipengaruhi oleh tingkat kepercayaan dan keterbukaan pemberian instruksi atasan kepada bawahan, kepedulian atasan terhadap hasil pekerjaan, keramahan atasan kepada bawahan, dan kehangatan hubungan antara atasan dan bawahan. Selanjutnya pada penelitian yang dilakukan oleh Wahyuningsih et al (2012), menyimpulkan bahwa komunikasi berpengaruh positif dan signifikan terhadap motivasi kerja pegawai. Lebih lanjut, hasil penelitian 
Wahyuningsih et al menyimpulkan bahwa semakin meningkatnya komunikasi maka motivasi kerja pegawai juga mengalami peningkatan.

Berdasarkan hasil analisis, diperoleh $\mathrm{t}_{\text {hitung }}$ lebih besar daripada $t_{\text {tabel }}(2,819>2,005)$ atau signifikansi t lebih kecil dari 5\% (0.007 < 0.050$)$ dan nilai koefisien regresi standardize $(0,288)$ bertanda positif, maka dapat disimpulkan bahwa Terdapat pengaruh positif dan signifikan antara kompensasi terhadap motivasi kerja pegawai. Artinya, semakin tinggi kompensasi yang diterima oleh pegawai, maka akan semakin tinggi motivasi kerja pegawai Dinas Pendapatan, Pengelolaan Keuangan dan Aset Daerah Kabupaten Soppeng. sebaliknya, semakin rendah kompensasi yang diterima oleh pegawai, maka akan semakin rendah pula motivasi kerja pegawai Dinas Pendapatan, Pengelolaan Keuangan dan Aset Daerah Kabupaten Soppeng.

Hasil penelitian ini sejalan dengan penelitian yang dilakukan oleh Prasastono (2012), bahwa terdapat pengaruh positif dan signifikan antara kompensasi terhadap motivasi kerja pegawai. Selanjutnya Nugroho \& Kunartinah (2012), juga menyimpulkan bahwa kompensasi berpengaruh positif dan signifikan terhadap motivasi kerja di Sekretariat Daerah Kabupaten Pekalongan.

Berdasarkan hasil analisis, diperoleh $\mathrm{F}_{\text {hitung }}$ lebih besar daripada $\mathrm{F}_{\text {tabel }}(34,149>2,78)$ atau signifikansi F lebih kecil dari 5\% $(0.000<0.050)$, maka dapat disimpulkan bahwa secara bersamasama (simultan) variabel bebas yang terdiri dari kepemimpinan (X1), komunikasi (X2) dan kompensasi (X3) berpengaruh signifikan terhadap variabel terikat yaitu motivasi (Y). Hal ini berarti apabila kepemimpinan, komunikasi dan kompensasi dapat ditingkatkan secara bersamasama maka akan berdampak pada peningkatan motivasi kerja pegawai Dinas Pendapatan, Pengelolaan Keuangan dan Aset Daerah Kabupaten Soppeng. Begitupun sebaliknya jika kepemimpinan, komunikasi dan kompensasi menurun secara bersama-sama maka akan mengakibatkan penurunan motivasi kerja pegawai Dinas Pendapatan, Pengelolaan Keuangan dan Aset Daerah Kabupaten Soppeng.

Untuk menentukan variabel bebas yang paling dominan mempengaruhi variabel terikat dapat dilihat dari koefisien regresi terstandarisasi (atau beta). Nilai yang paling tinggi mengindikasikan variabel yang paling dominan. Berdasarkan hasil penelitian dapat disimpulkan bahwa variabel kepemimpinan (X1) adalah variabel yang paling dominan mempengaruhi motivasi kerja (Y), dengan koefisien beta sebesar 0,404 , kemudian kompensasi sebesar 0,288, serta yang paling rendah yakni komunikasi sebesar 0,261. Hasil ini menunjukkan bahwa, kepemimpinan memegang peranan utama dalam meningkatkan motivasi kerja pegawai kemudian diikuti oleh pemberian kompensasi yang memadai serta yang terakhir adalah faktor komunikasi.

\section{KESIMPULAN}

Berdasarkan hasil penelitian pada responden yaitu pegawai Dinas Pendapatan, Pengelolaan Keuangan dan Aset Daerah (DPPKAD) Kabupaten Soppeng, maka dapat disimpulkan beberapa hal sebagai berikut: (1) Kepemimpinan berpengaruh positif dan signifikan terhadap motivasi kerja pegawai Dinas Pendapatan, Pengelolaan Keuangan dan Aset Daerah Kabupaten Soppeng. (2) Komunikasi berpengaruh positif dan signifikan terhadap motivasi kerja pegawai Dinas Pendapatan, Pengelolaan Keuangan dan Aset Daerah Kabupaten Soppeng. (3) Kompensasi berpengaruh positif dan signifikan terhadap motivasi kerja pegawai Dinas Pendapatan, Pengelolaan Keuangan dan Aset Daerah Kabupaten Soppeng. (4) Kepemimpinan, komunikasi dan kompensasi secara simultan (bersama-sama) berpengaruh positif dan signifikan terhadap motivasi kerja pegawai Dinas Pendapatan, Pengelolaan Keuangan dan Aset Daerah Kabupaten Soppeng.

\section{DAFTAR PUSTAKA}

Alice T.R. (2004). Hubungan Antara Komunikasi antar Pribadi Guru dan Motivasi Kerja Guru dengan Kinerja Guru SMUK BPK PENABUR Jakarta. Jurnal Pendidikan Penabur-No.03/Th.III

Hasibuan M.S.P. (2006). Manajemen Sumber daya Manusia. Jakarta: PT. Haji Masagung.

Hidayah S. \& Kukuh P. (2011). Analisis Pengaruh Disiplin Kerja dan Komunikasi terhadap Kinerja dengan Mediasi Motivasi Kerja Pegawai (studi kasus Pegawai pada Dinas Kelautan dan Perikanan Kota 
Semarang). Jurnal Ekonomi Manajemen Akuntansi, Vol 19, No. 31.

Mulyadi D., Asep M. \& Cipto G. (2013). Analisis Peran Kepemimpinan terhadap Motivasi Kerja Pegawai pada Departemen Fasilitas Umum dan Penataan Lingkungan Perum Peruri.

Nugroho, Agus D. \& Kunartinah. (2012). Analisis Pengaruh Kompensasi dan Pengembangan Karier terhadap Kepuasan Kerja dengan Mediasi Motivasi Kerja (studi pada PNS di Sekretariat Daerah Kabupaten Pekalongan). Jurnal Bisnis dan Ekonomi (JBE), September 2012, Hal 153 - 169.

Prasastono N. (2012). Pengaruh Gaya Kepemimpinan dan Kompensasi terhadap Motivasi Kerja Karyawan Hotel Muria
Semarang. Jurnal Dinamika Kepariwisataan Vol. XI No.2, Oktober 2012.

Robbins S.P. (2006). Perilaku Organisasi, Jakarta : Indeks.

Sugiyono. (2009). Metode Penelitian Kuantitatif, Kualitatif dan $R \& D$. Bandung: Alfabeta

Thoha M. (2012). Perilaku Organisasi Konsep Dasar dan Implikasinya. Jakarta: PT Raja Grafindo Persada.

Uno H.B. (2012). Teori Motivasi \& Pengukurannya, Jakarta: PT. Bumi Aksara.

Wahyuningsih S., Rahayu S.B. \& Istiatin. (2012). Pengaruh Kepemimpinan, Disiplin Kerja dan Komunikasi terhadap Motivasi Kerja Pegawai Badan Kepegawaian Daerah Kota Surakarta. Jurnal Manajemen Bisnis Syariah, No:02/ Th.VI/ Agustus 2012 - Januari 2013. 